\title{
Silicon-Light: a European project aiming at high efficiency thin film silicon solar cells on foil
}

\author{
W. Soppe ${ }^{1, a}$, J. Krc ${ }^{2}$, K. Leitner ${ }^{3}$, F.-J. Haug ${ }^{4}$, M. Duchamp ${ }^{5}$, G. Sanchez Plaza ${ }^{6}$, and Q.-K. Wang ${ }^{7}$ \\ 1 Energy Research Centre of the Netherlands (ECN), 5656 AE Eindhoven, The Netherlands \\ ${ }^{2}$ University of Ljubjana, 121000 Ljubjana, Slovenia \\ 3 Umicore Thin Film Products AG, 9496 Balzers, Liechtenstein \\ 4 Ecole Polytechnique Federale de Lausanne, 1015 Lausanne, Switzerland \\ ${ }^{5}$ Forschungszentrum Jülich, 52428 Jülich, Germany \\ 6 Universidad Politechnica de Valencia, 46022 Valencia, Spain \\ 7 Shanghai Jiaotong University, Shanghai, P.R. China
}

Received: 29 July 2013 / Received in final form: 20 November 2013 / Accepted: 6 January 2014 Published online: 7 July 2014

(C) Soppe et al., published by EDP Sciences, 2014

\begin{abstract}
In the European project Silicon-Light we developed concepts and technologies to increase conversion efficiencies of thin film silicon solar cells on foil. Main focus was put on improved light management, using NIL for creating light scattering textures, improved TCOs using sputtering, and improved silicon absorber material made by PECVD. On foil we achieved initial cell efficiencies of $11 \%$ and on rigid substrates stable efficiencies of $11.6 \%$ were achieved. Finally, the project demonstrated the industrial scale feasibility of the developed technologies and materials. Cost of ownership calculations showed that implementation of these technologies on large scale would enable the production of these high efficiency solar modules at manufacturing cost of $0.65 € / \mathrm{Wp}$ with encapsulation costs $(0.20 € / \mathrm{Wp})$ being the dominant costs. Life cycle analysis showed that large scale production of modules based on the technologies developed in Silicon-Light would have an energy payback time of 0.85 years in Central European countries.
\end{abstract}

\section{Introduction}

In order to be competitive with other PV technologies, thin film silicon PV needs higher efficiencies and lower production cost levels than the presently available technologies. In the EU project Silicon-Light we addressed both issues. By improving the light management, the silicon absorber layers and the front-side TCO, the project aimed at stable cell efficiencies of more than $11 \%$. In the project these developments were up-scaled to large area roll-to-roll fabrication methods, potentially leading to significant reduction in production costs in comparison with conventional batch production on glass panels.

The project Silicon-Light was carried out by a consortium of 9 partners which were strongly complementary in the fields which are dealt with. The activities were separated into 5 different work packages: 1 ) light management, 2) silicon absorber layers and interfaces; 3) TCOs; 4) high efficiency cells; 5) integration and upscaling. In the first half of the project, the focus was on the development of the individual elements of the cells (WP 1-3). The best and most promising results then were used in the second

\footnotetext{
${ }^{\mathrm{a}}$ e-mail: soppe@ecn.nl
}

half of the project to make high efficiency cells (WP 4), followed by up-scaling and implementation in pilot scale production in WP 5.

\section{Results}

\subsection{Light management}

Through a careful interplay between opto-electrical modeling and device fabrication we have identified ideal 2D periodic textures for the back reflector in nip/nip a-Si $/ \mu$ c-Si tandem cells (a-Si cell on top).

The typical device structure used in the modeling is shown in Figure 1. Note that this device structure contains two light management layers: one synthetic structure made by nano-imprint lithography (NIL) on the substrate foil, and one natural structure on the $2000 \mathrm{~nm} \mathrm{ZnO:B}$ layer, grown by LPCVD.

In the modeling, the non-conformal growth of the $\mathrm{ZnO} / \mathrm{Ag}$ back contact and of the silicon layers was taking into account [1]. This was done by introducing an isotropic growth factor $g$ as explained in Figure 2. Using this empirical growth model, in which the factor $g$ was determined 


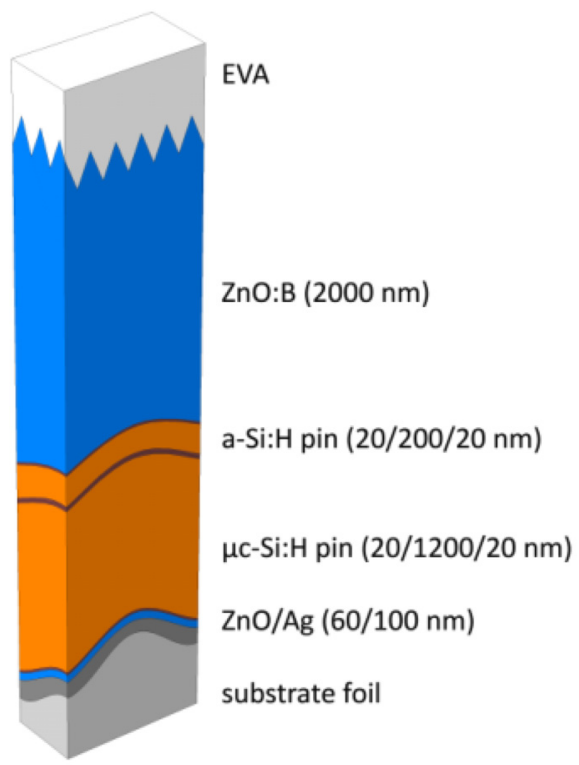

Fig. 1. Structure of micromorph a-Si:H/ $/ \mu \mathrm{c}-\mathrm{Si}: \mathrm{H}$ solar cell as used in the opto-electrical simulations.

by analyzing cross sections of $\mathrm{ZnO} / \mathrm{Ag} /$ nip-Si layer stacks on various substrate morphologies we were able to achieve a very realistic description of the stack geometry as input for the optical modeling.

The optical modeling was used to determine the optimum 2D periodic texture of the rear side reflector/contact, taking into consideration that the structures should be experimentally feasible to make and that textures with high aspect ratios commonly lead to formation of micro-cracks in the silicon layers [2]. We found that to avoid formation of micro-cracks, the opening angle $\varphi$ of the structures at the growth surface (see Fig. 3) should be larger than $130^{\circ}$.

We selected 2D-sinusoidal structures as experimentally most feasible structures, and then determined the $J_{s c}$ that can be achieved for a-Si/ $\mu$ c-Si tandem devices with a bottom layer thickness of $1200 \mathrm{~nm}$, for various periods and heights of the structures [3]. The results of $J_{s c}$ of the bottom cell are presented in Figure 4, and indicate that currents of more than $14 \mathrm{~mA} / \mathrm{cm}^{2}$ could be achieved for 2Dsinusoidal structures with a period of about $1100 \mathrm{~nm}$ and a height of about $1000 \mathrm{~nm}$. These optically ideal structures however do not fulfill the $\varphi>130^{\circ}$ criterion and will lead to substantial crack formation in the micro-crystalline silicon layers. To fulfill the $\varphi>130^{\circ}$ criterion, the height of the sinusoidal structures must be decreased to about $300 \mathrm{~nm}$ and for these structures the model predicts maximum currents of about $12.5 \mathrm{~mA} / \mathrm{cm}^{2}$. Further improvements can be done by including low-absorbing doped $\mathrm{SiO}_{x}$ layers and anti-reflecting coatings in the structure.

These 2D periodic textures were successfully made as small masters and subsequently up-scaled to larger shims for roll-to-roll Nano-Imprint-Lithography (NIL). Finally the industrial feasibility of the concept was demonstrated by imprinting these textures on foil of a width of $30 \mathrm{~cm}$ (see Fig. 5).

\subsection{Silicon layers and interfaces}

Detailed analysis of interfaces by advanced microcopy techniques showed the diffusion of conductive TCO material in voids along the grain boundaries in microcrystalline silicon [4]. In interplay with the texturization activities, we identified growth regimes of microcrystalline silicon where crack formation on textured substrates can be reduced largely, reducing shunting of the solar cells.

We also applied electron energy-loss spectroscopy (EELS) to determine the parasitic absorption losses in the $\mathrm{Ag}$ back reflector. EELS can be used to measure the energy-loss that electrons suffer when travelling through a sample in a TEM. The physical processes involved in energy-loss events can be (i) band gap transitions, (ii) plasmon collective oscillations and (iii) interatomic transitions. Therefore, EEL spectra can be used to provide information about (a) the band gap energy, (b) the carrier density (through the plasmon energy) and (c) the local atomic composition with nanometer spatial resolution [5]. With recent improvements in TEM technology, energy losses as low as $1 \mathrm{eV}$ are accessible, allowing the measurement of surface and bulk plasmon resonances in $\mathrm{Ag}$ with high spatial resolution [6]. Previously, plasmon absorptions were measured in back-contact Ag layers using visible light leading to a limited spatial resolution. Figure 6a shows a Scanning TEM (STEM) image of a Ag back reflector grown on a $\mathrm{ZnO}$ back contact. The $\mathrm{Ag}$ grain sizes are between 50 and $200 \mathrm{~nm}$ which is much smaller than the diameter of the optical beam previously used to probe plasmon losses. The TEM beam was positioned at the surface and at the centre of a grain, as indicated in Figure $6 \mathrm{a}$, to measure plasmon absorption. The two spectra are shown in Figure 6b. A bulk plasmon peak at $3.8 \mathrm{eV}$ is visible when measuring at the center of the Ag crystal. More importantly, when measuring at the Ag grain edge, where the reflection of light in solar cells happens, a strong absorption peak, centered at $\sim 2.8 \mathrm{eV}$ and extended down to $2 \mathrm{eV}$, is present. As the absorption range of a thin-film Si solar cell is between $\sim 1.5$ and $3 \mathrm{eV}$, this peak is indicative of parasitic absorption and can decrease the performance of the solar cell in case of thin absorber layers [7].

One way to reduce the absorption due to the $\mathrm{Ag} / \mathrm{Si}$ surface plasmon peak is to apply a dielectric buffer layer between the $\mathrm{Ag}$ and Si layers [8]. This approach could be one of the positive side-effects of including a $\mathrm{ZnO}$ layer between the Ag back reflector and the nip solar cell. It has also been shown that annealing the $\mathrm{Ag}$ layer before the $\mathrm{Si}$ PECVD process improves the reflectivity below $\sim 1000 \mathrm{~nm}$ (above $\sim 1.2 \mathrm{eV}$ ) [9]. We have not yet assessed whether this effect is caused by a reduction in the Ag plasmon absorption or by reduction of other parasitic absorptions.

EELS was also used to determine the boron (B) concentration profile in the p- and adjacent layers. The p-layer in a nip Si solar cell should be both highly conductive and transparent in the absorption range of the Si layer. The conductivity can be adjusted by varying the B concentration, while the transparency window can be extended by adding either carbon (C) or oxygen. The drawback of 
W. Soppe et al.: Silicon-Light: a European project aiming at high efficiency thin film silicon solar cells on foil
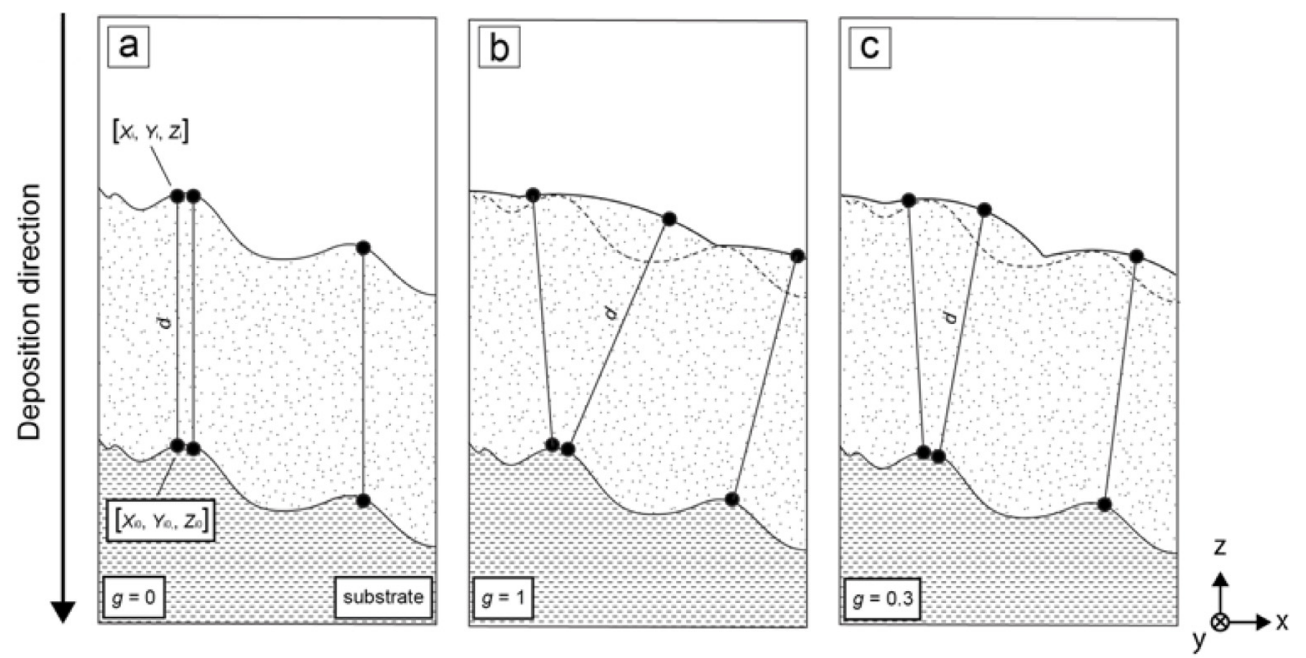

Fig. 2. Vertical cross-sections of a thin-film layer grown on a substrate as calculated by the developed 3-D growth model by considering: (a) fully conformal $(g=0)$, (b) fully isotropic $(g=1)$ and (c) combined growth type $(g=0.3)$. The dashed lines on the top surfaces in (b) and (c) indicate the reference texture obtained by conformal growth type.

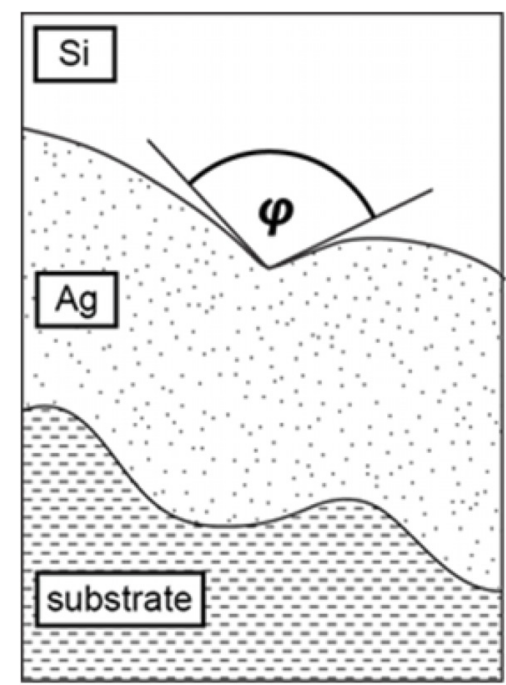

Fig. 3. Opening angle $\varphi$.

increasing the $\mathrm{C}$ content is a decrease in the conductivity. Therefore, an optimal C/B ratio has to be found to fulfill the requirements for an a-Si solar cell. Figure 7 a shows calculations of the expected cell efficiency by varying the optical band gap $E_{g}$ and the activation energy $E_{a c t}$. The best cell efficiency is expected for high $E_{g}$ and low $E_{a c t}$ of the p-a-SiC layer. By varying the experimental growth conditions within a roll-to-roll compatible process line, we are striving to reach this high efficiency region. The values of the experimentally accessible region are shown by the black dashed line in Figure 7a and show cells with an efficiency of close to $8 \%$ [10].

In practice, this layer has to remain as thin as possible (i.e. a few nm) to limit the optical absorption and the carrier recombination in the layer. A standard characterization tool to directly access to doping concentration is secondary ion mass spectrometry (SIMS) however SIMS

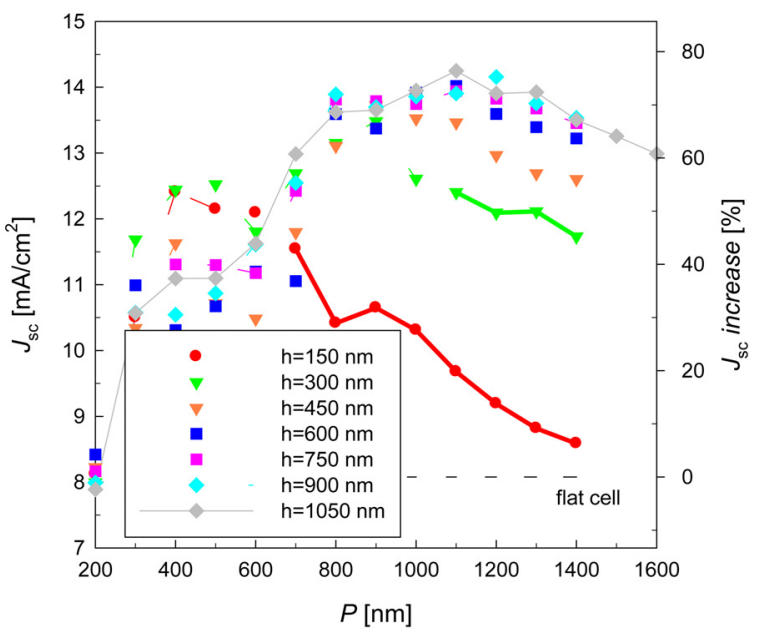

Fig. 4. $J_{s c}$ calculated for the bottom cell of a-Si/ $\mu \mathrm{c}-\mathrm{Si}$ tandem devices with a bottom layer thickness of $1200 \mathrm{~nm}$, for various periods and heights of 2D sinusoidal structures of the rear side reflector. Only the bold part of the curves fulfill the criterion $\varphi>130^{\circ}$.

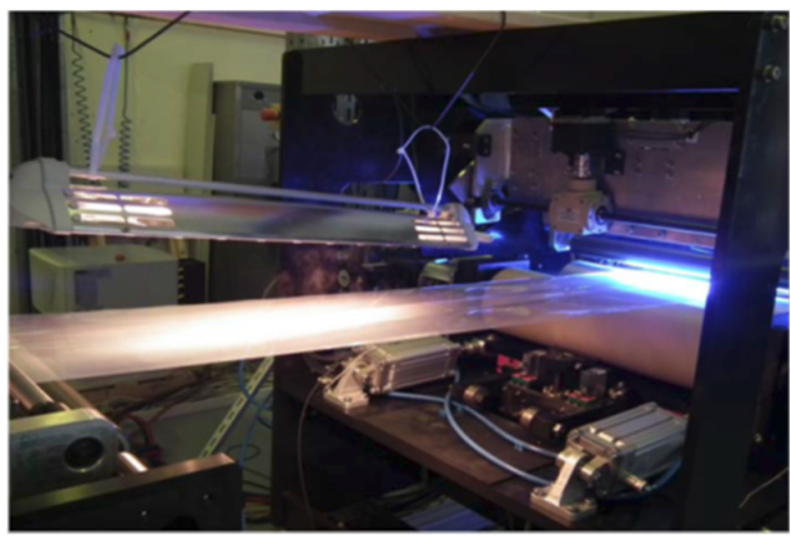

Fig. 5. Nanoptics R-2-R-pilotmachine demonstrating NIL on PEN film. 

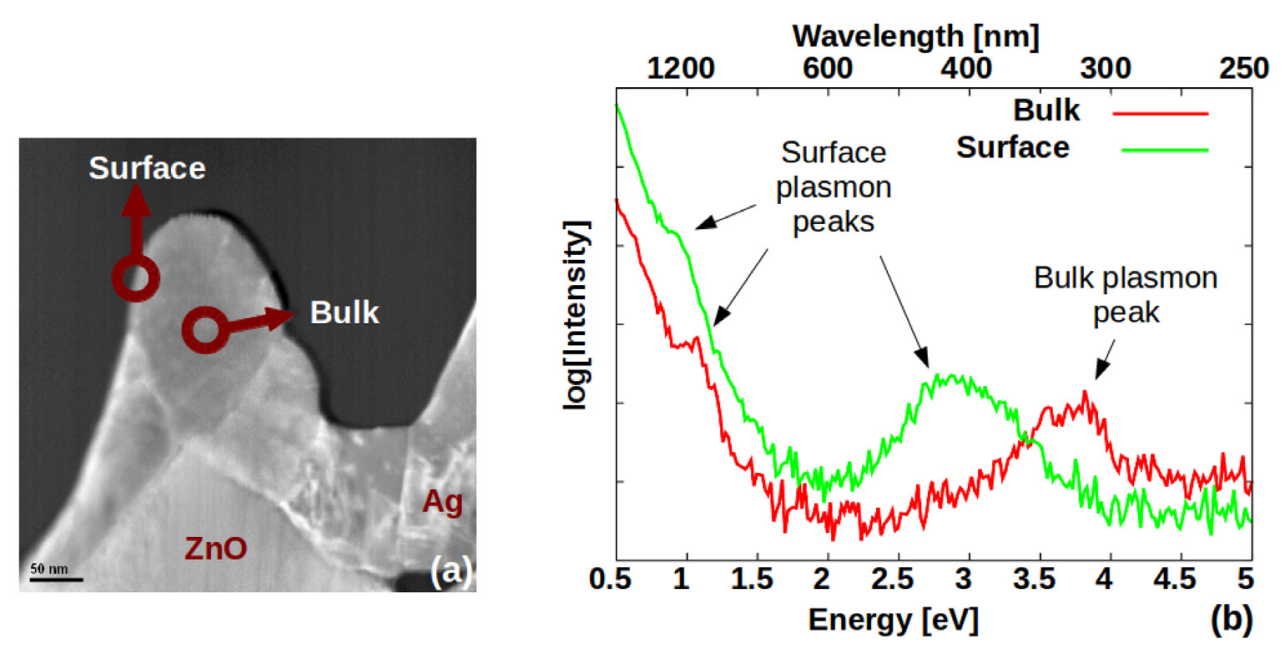

Fig. 6. (a) STEM image of an as-grown Ag back reflector on top of a $2 \mu \mathrm{m}$ thick ZnO layer. The "bulk" and "surface" locations refer to positions where EEL spectra were recorded. (b) EEL spectra taken at the "bulk" and "surface" regions.
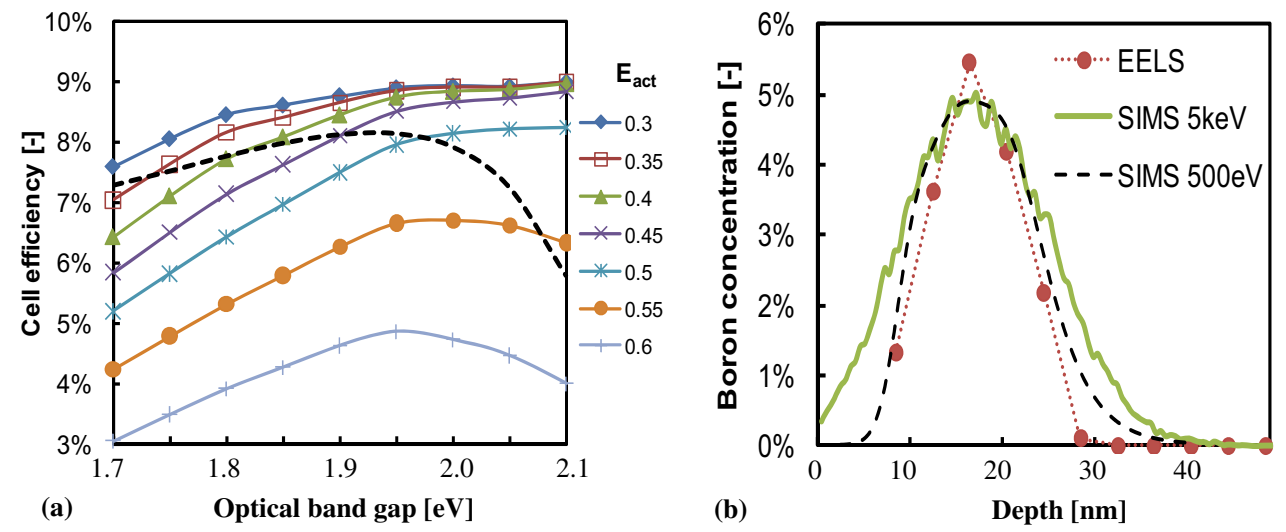

Fig. 7. (a) Calculated efficiency of a-Si solar cells as a function of the optical band gap of the p-a-SiC layer for seven values of the activation energy $\left(E_{a c t}\right)$. The efficiencies for grown solar cells are given by the dashed line. (b) Relative boron concentration profiles determined by EELS (markers) and SIMS (lines).

has limited depth resolution and averages the doping concentration over distances of several micrometers, which is not suitable for devices on rough substrates. To overcome this problem, we have measured core loss signals using EELS [11]. Recorded graphs are shown in Figure 7b. The relative $\mathrm{B}$ concentration measured by EELS is higher when compared to SIMS values at the center of the layer. The thickness of the p-layer is determined to be about $15 \mathrm{~nm}$.

Although core-level EELS measures the concentration of $\mathrm{B}$ atoms and ions, it is not sensitive to the active dopant concentration. In contrast, low-loss EELS shows an absorption peak related to the plasmon absorption, which is located at $17.2 \mathrm{eV}$ for $\mathrm{Si}$. We examined a test sample which consisted of a stack of three $\sim 200 \mathrm{~nm}$ SiC layers with no (i-SiC), standard ( $\mathrm{p}+-\mathrm{SiC})$ and double $(\mathrm{p}++-\mathrm{SiC})$ amounts of $\mathrm{B}$ doping sandwiched between standard back $(\mathrm{ZnO} / \mathrm{Ag})$ and front (ITO) contact layers. In Figure 8, the plasmon energy (open symbols) is plotted as a function of depth. For comparison, a SIMS profile of the B concentration is shown as a solid line. In order to estimate the relative $\mathrm{B}$ concentration obtained by SIMS, we assume that

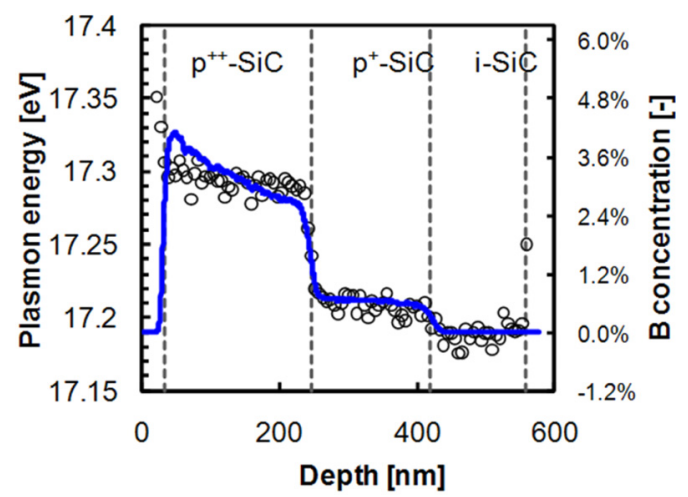

Fig. 8. Plasmon energy determined by EELS (data points) and boron profile from SIMS (line). The dashed lines indicate the interfaces in the sample.

the total density of atoms is $5 \times 10^{22} \mathrm{~cm}^{-3}$; the typical error when determining B in Si is 10 at.\% [12]. We observe a strong relationship between the $\mathrm{B}$ concentration and the 
W. Soppe et al.: Silicon-Light: a European project aiming at high efficiency thin film silicon solar cells on foil

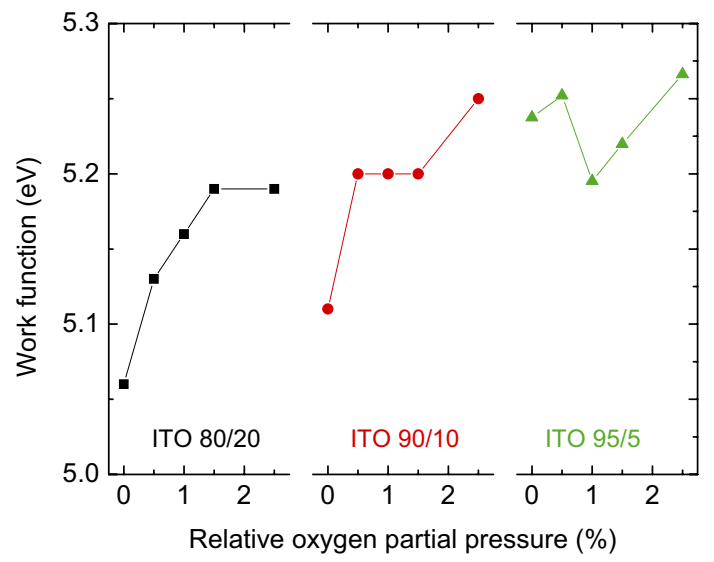

Fig. 9. Dependence of the work function on target composition and oxygen partial pressure during deposition.

plasmon energy. By assuming that the density of atoms and the carrier mobility are independent of the B-doping level, we can deduce that the increase in B concentration increases the valence electron density. Furthermore, the TCO front and back contacts and the Ag layer can be identified by the measurements of their plasmon energies at the expected depths (not shown in the graph).

\subsection{TCO development}

TCO development in the project Silicon-Light was focused on development of new TCOs by sputtering. The reference material in these investigations was ITO and one of the topics was to eliminate a possible collection barrier between TCO and p-layer. Band diagram analysis shows that the interface between commonly used TCOs like AZO and ITO and the p-layer provides such a theoretical collection barrier. This barrier can be reduced if the work function of the TCO can be increased. Exact determination of the work function of sputtered TCOs is not straightforward but we established a method to determine work functions of TCOs accurately and reproducible by Kelvin Probe measurements. Applying reactive sputtering, with oxygen as reactant we were successful in increasing the work function of ITO [13]. Figure 9 shows the results of these experiments which indicate that highest work functions are obtained for sputter targets with the highest indium content, and with highest oxygen concentrations during the sputter process. However, the $V_{o c} \mathrm{~s}$ of the a-Si cells that we made with these layers (see Fig. 10) do not follow straightforwardly the trend of the work function, but the correlation between $V_{o c}$ and oxygen pressure seems to be statistically significant.

\subsection{High efficiency cells}

By combining best results from the light management activities, silicon-layer development and TCO development we were able to improve cell efficiencies significantly.

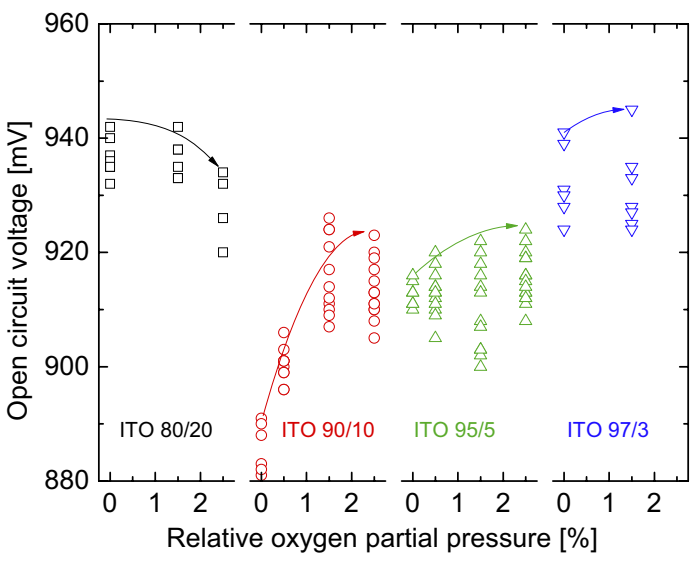

Fig. 10. Variation of the open circuit voltage $V_{o c}$ with the oxygen content in the sputtering plasma of the ITO front electrode.

The aim was to achieve a-Si/ $\mu$ c-Si tandem nip/nip devices with stabilized efficiencies of $11 \%$. For this purpose we had to improve both the $\mu \mathrm{c}$-Si bottom cells and the a-Si top cells. Applying NIL to fabricate textured back contacts, we were able to achieve $J_{s c}$ of $24 \mathrm{~mA} / \mathrm{cm}^{2}$ for single junction nip $\mu \mathrm{c}$-Si cells with a $\mu \mathrm{c}-\mathrm{Si}$ absorber layer of only $1000 \mathrm{~nm}$. These currents were obtained for both a random texture (replica of Asahi-U glass) and for $2 \mathrm{D}$ sinusoidal structures. Due to shunting through microcracks, however, the fill factors of the cells on the random texture were significantly lower than on the sinusoidal structures. Cross sectional TEM images (see Fig. 11) show the successful suppression of crack formation of $\mu \mathrm{c}$-Si cells grown on 2D sinusoidal structures [14].

To increase the current in the a-Si top cells, we applied p-doped $\mathrm{SiO}_{x}: \mathrm{B}$ as window layer. This is achieved by adding $\mathrm{CO}_{2}$ to the precursor gas mix during deposition [15]. Figure 12 shows the effect on the EQE in the blue wavelength regime. Best solar cells were achieved for a $\mathrm{CO}_{2} / \mathrm{SiH}_{4}$ ratio of 0.4 , with a $V_{o c}$ of $920 \mathrm{mV}$, $J_{s c}=14.6 \mathrm{~mA} / \mathrm{cm}^{2}$ and a $F F$ of $68 \%$ leading to an efficiency of $9.0 \%$.

Finally we made nip a-Si/ $\mu$ c-Si tandem cells, both on glass and on steel substrates.

\subsubsection{Tandem cells on glass substrates}

The stack configuration of these cells was: glass/ZnO:B/Ag/ZnO/nip $\mu$ c-Si/ZnO/nip a-Si/ZnO.

The glass was covered with a 5 micron thick layer of $\mathrm{ZnO}$ grown by LPCVD. The natural texture of this $\mathrm{ZnO}$ layer serves as the light scattering texture of the back reflector, which was completed by sputtering a Ag layer plus a thin $\mathrm{ZnO}$ buffer layer on top of it.

Best nip tandem cells on glass had an initial efficiency of $13.2 \%$ and a stable efficiency of $11.6 \%$. This device contains a $\mu \mathrm{c}-\mathrm{Si}$ bottom cell with a thickness of 1.7 micron and a intermediate reflector layer of $\mathrm{ZnO}$ with a thickness of 1.1 micron. The spectral response of this cell is shown in Figure 13. 


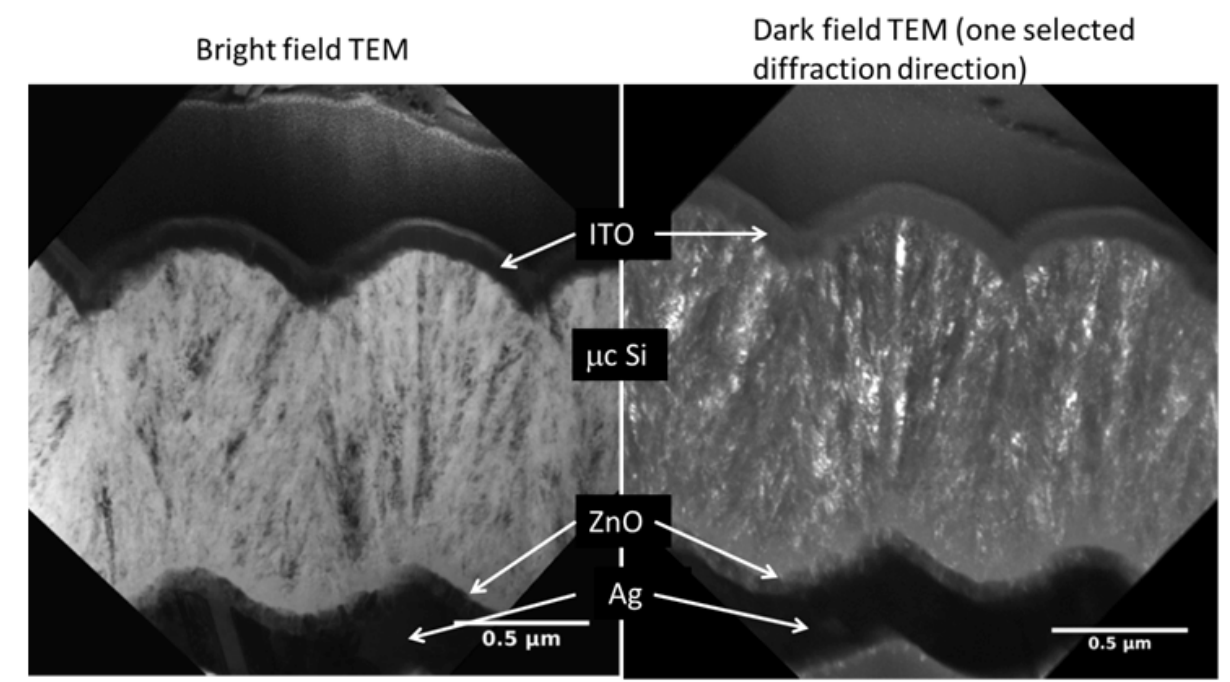

Fig. 11. Cross sectional TEM images made of microcrystalline silicon solar cells made on steel foil with a 2D sinusoidal texture.

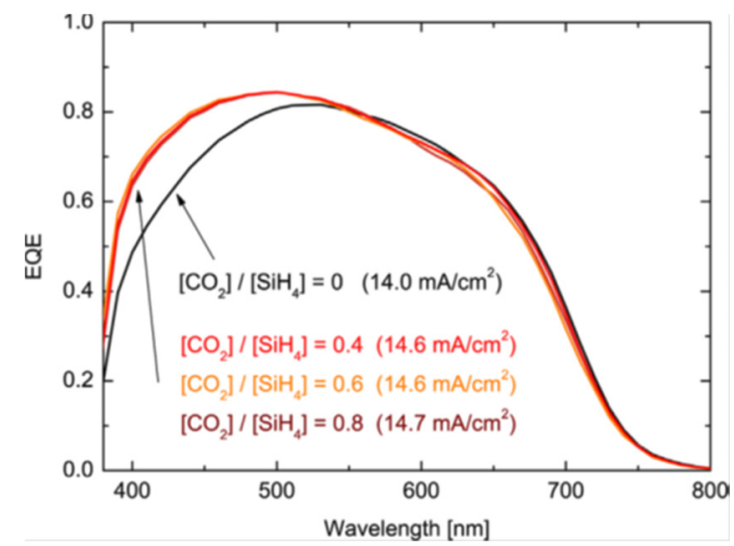

Fig. 12. EQEs of a-Si nip solar cells with p-layers made from $\mathrm{SiO}_{x}$ with increasing oxygen content.

\subsubsection{Tandem cells on steel foil}

The stack configuration of the tandem cells on steel foil is sketched in Figure 14. On the foil we apply a UV curing lacquer for NIL, which also serves as an insulating layer to enable monolithic series interconnection. The metal grid is applied to enable current collection from the front TCO: a $80 \mathrm{~nm}$ thin ITO layer.

As for the single junction $\mu \mathrm{c}-\mathrm{Si}$ cells on foil, we applied both a random master (replica of Asahi-U texture) and a $2 \mathrm{D}$ periodic (sinusoidal) master to make imprints in the UV lacquer. The fill factor of the tandem cells appear to be less vulnerable for microcracks in the $\mu$ c-Si bottom cell and so we obtained very similar results for both types of textures. For tandem cells with a bottom cell thickness of $1000 \mathrm{~nm}$ and a top cell thickness of $300 \mathrm{~nm}$, we obtained (initial) efficiencies of $11.0 \%\left(V_{o c}=1381 \mathrm{mV} ; J_{s c}\right.$ topcell $=11.84 \mathrm{~mA} / \mathrm{cm}^{2} ; J_{s c}$ bottom-cell $=12.31 \mathrm{~mA} / \mathrm{cm}^{2}$, $F F=67 \%$ ). The spectral response curve of these cells is shown in Figure 15. Note that these cells do not contain an intermediate reflector yet.

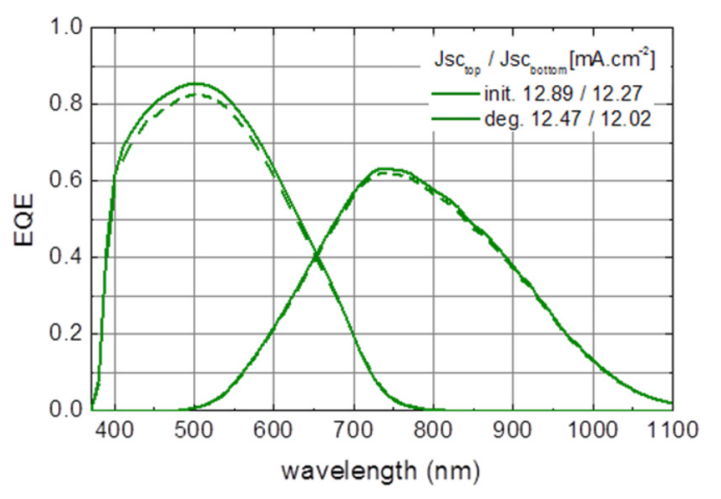

Fig. 13. EQEs of the best stable device in initial (full line) and stable state (dashed line).

\subsection{Implementation in pilot production and calculations of cost and environmental impact}

Implementation of project results into pilot production was hindered by financial problems at the end user (VHF Technologies). Nevertheless they were able to increase the stabilized efficiency for a-Si/a-Si tandem cells in their production line towards $8.0 \%$ by implementing light management technologies developed by the project.

VHF Technologies applies ITO as top TCO and cost reductions can be realized if the indium consumption could be reduced. For this purpose we investigated cosputtering of ITO and AZO (Al doped ITZO). In order to simulate co-sputtering of ITO and AZO, a chess-pattern sputtering target containing both ITO and AZO tiles was prepared. An industrial scale target was prepared by Umicore for VHF Technologies PVD machines. Small ITO and AZO segments were bonded onto a molybdenum backing plate in a chess pattern design (see Fig. 16). Using this target, single junction a-Si cells and a-Si/a-Si tandem cells were made in the production line and compared with reference cells with ITO as top TCO. 
W. Soppe et al.: Silicon-Light: a European project aiming at high efficiency thin film silicon solar cells on foil
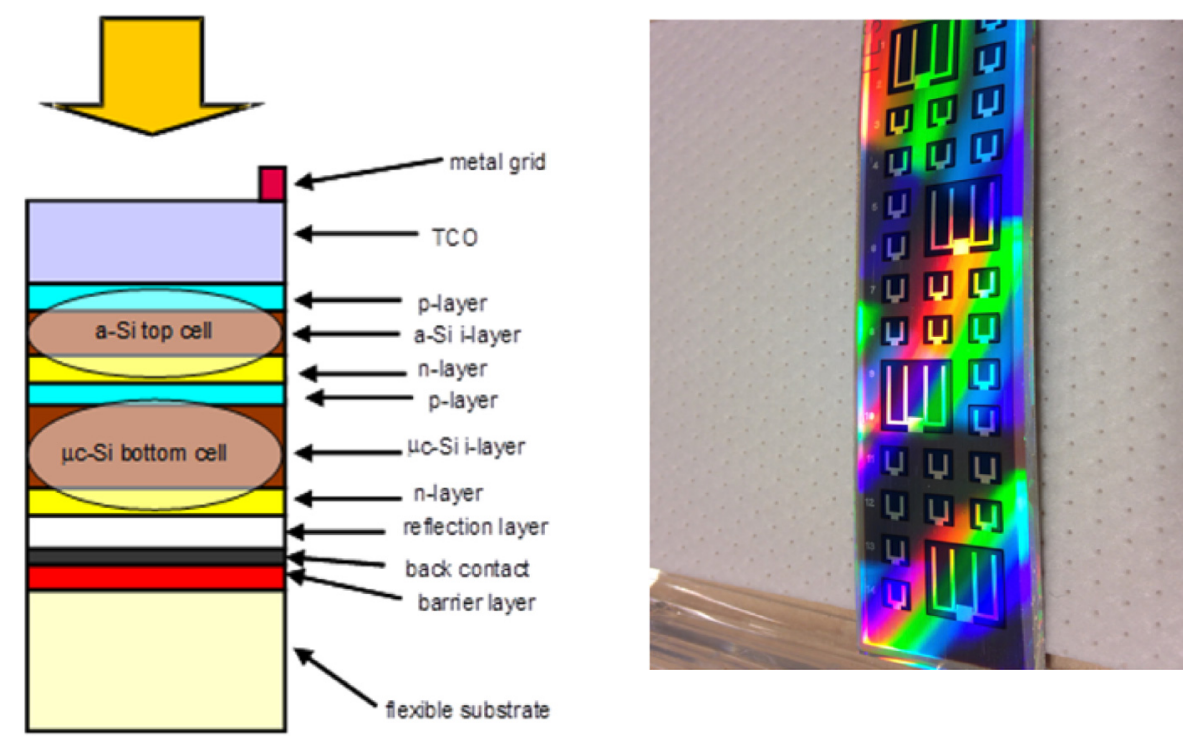

Fig. 14. Left: Stack configuration of tandem cells on (steel) foil. The UV curing lacquer for NIL is indicated as "barrier layer"; right: a photograph showing $4 \times 4 \mathrm{~mm}^{2}$ and $10 \times 10 \mathrm{~mm}^{2}$ cells. The rainbow effect is due to the $2 \mathrm{D}$ structure of the back contact.

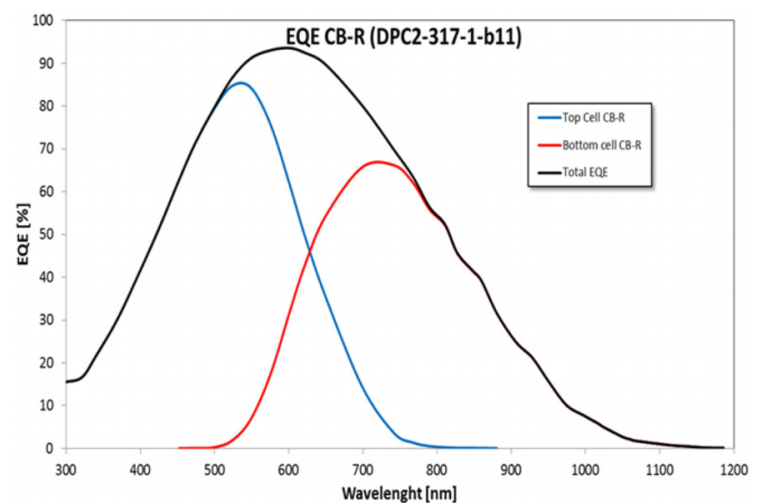

Fig. 15. EQE spectrum of a $11 \%$ efficiency tandem cell on steel foil.

Table 1. IV characteristics of a-Si/a-Si tandem cells with top TCO made with ITO/AZO mosaic target with various amounts of oxygen added to the sputter gas argon.

\begin{tabular}{ccccc}
\hline Target & $\begin{array}{c}\text { Oxygen } \\
\text { addition }\end{array}$ & $V_{o c}(\mathrm{~V})$ & $\begin{array}{c}J_{s c} \\
\left(\mathrm{~mA} / \mathrm{cm}^{2}\right)\end{array}$ & $F F(\%)$ \\
\hline ITO & ITO std & 1.739 & 5.54 & 72.4 \\
\hline \multirow{2}{*}{ ITO/AZO } & $3 \%$ oxygen & 1.772 & 5.46 & 70.2 \\
& 2\% oxygen & 1.711 & 5.49 & 70.1 \\
& $1 \%$ oxygen & 1.824 & 5.51 & 72.5 \\
\hline
\end{tabular}

The solar cells made with the ITO/AZO top TCO were as good as the reference cells. In Table 1 an overview is given of an a-Si/a-Si tandem cells showing that high $V_{o c} \mathrm{~s}$ and good fill factors can be obtained with these TCOs.

Using data available in the public literature e.g. $[16,17]$ - we also attempted a cost and an environmental analysis of the production process of thin film silicon solar cells on foil, in which the technologies developed in the project silicon light would be implemented. So we

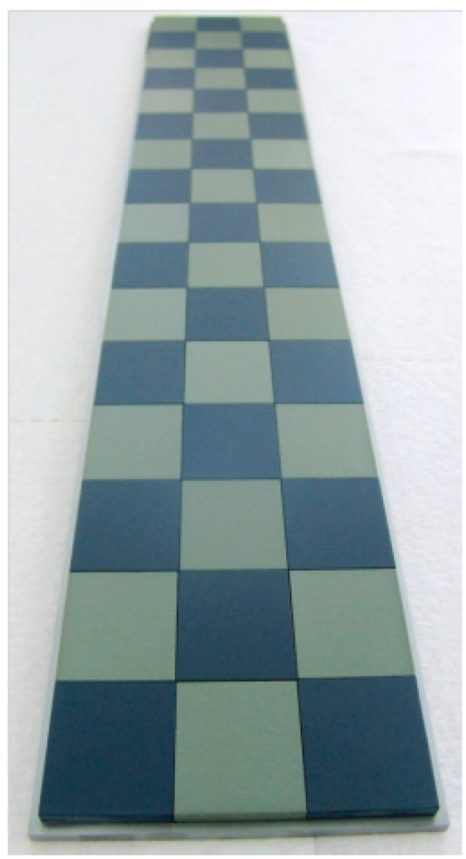

Fig. 16. ITO/AZO mosaic target (chess pattern) for sputtering tests under industrial conditions at VHF Technologies. Dimension $750 \times 125 \mathrm{~mm}, 48$ segments.

assumed a production line of a-Si/ $\mu \mathrm{c}-\mathrm{Si}$ tandem cells on steel foil, with a capacity of $120 \mathrm{MWp} / \mathrm{yr}$ and a module efficiency of $10 \%$. In such a line, modules could be produced at a cost of $650 € / \mathrm{kWp}$, which can be divided in $159 € / \mathrm{kWp}$ Fixed Costs, $156 € / \mathrm{kWp}$ Operational Costs and $334 € / \mathrm{kWp}$ Material Costs. So the largest costs in the production are Materials Costs and if we look at a breakdown of the costs per process step (Fig. 17) we see that these costs are dominated by the material costs involved in the "final assembly", namely the cost for lamination 


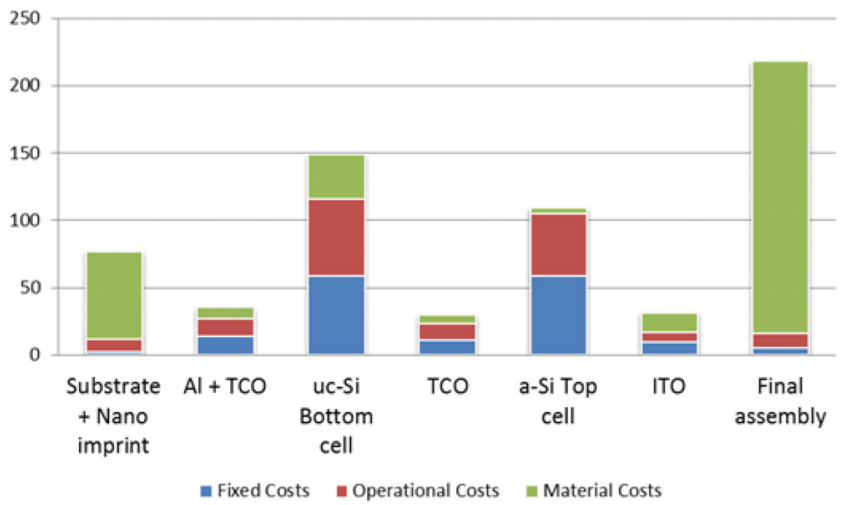

Fig. 17. Cost break down per major process step. Series interconnection, lamination and assembly of junction box are comprised in the "final assembly".

(ETFE) and the junction box. Most significant cost reductions could therefore be achieved if cheaper encapsulants could be applied.

A life cycle assessment was carried out in which three kinds of flexible thin-film silicon PV modules were compared. A comparison was made between an a-Si module (benchmark-1), an a-Si/ $\mu$ c-Si micromorph module (benchmark-2) and an a-Si/ $\mu$ c-Si micromorph module containing the improvements developed in the SiliconLight project (Silicon-Light). The three modules differed from each other in the configurations of the photoactive layer as well as in the texture of the back-reflector.

The analyses show that the Silicon-Light PV module, i.e, the device implementing the technology achievements of the Silicon-Light project, shows the best environmental profile of the three devices. This is because of the advanced back-reflector texture fabricated by nanoimprint lithography. The advanced texture allows the application of a thinner photoactive layer while maintaining a high module efficiency (10\%). This photoactive layer of the SiliconLight device consists of a $180 \mathrm{~nm}$ a-Si and a $1000 \mathrm{~nm} \mu \mathrm{c}-\mathrm{Si}$ layer, whereas without NIL a (flat) bottom cell of more than $2000 \mathrm{~nm}$ would be required to achieve the same $J_{s c}$.

The environmental profile of the Silicon-Light PV module is characterized by an embedded energy of $617.5 \mathrm{MJ} / \mathrm{m}^{2}$, an energy payback time of 0.85 years and a carbon footprint of $20.1 \mathrm{~g} \mathrm{CO}_{2}$-eq./ $\mathrm{kWh}$.

\section{Conclusions}

Silicon-Light is a European FP7 project that aimed at the development of high efficiency thin film silicon solar cells on foil. The project focused on (a) improved light management through implementation of nano-imprint lithography; (b) improved silicon material and (c) novel TCO materials made by sputtering. In Silicon-Light we investigated methods to create light-scattering textures at the rear side of the cell. For the fabrication of these textures, with structures on nanometer scale, methods from the semiconductor industry like e-beam lithography were applied. To demonstrate that these textures can be manufactured on large scale, these methods were combined with large scale production methods for nano-imprint lithography (NIL) which are used in the holographic industry.

Another aim of the project was to develop new Transparent Conductive Oxide (TCO) layers for thin film silicon solar cells. TCO layers are needed to collect the generated current at the front side of the solar cell. Indium Tin Oxide (ITO) is technically a good candidate but the scarceness of indium requires to investigate alternative materials. Zincoxide $(\mathrm{ZnO})$ is a possible alternative but has certain disadvantages related to its stability in humid environments. In Silicon-Light new TCOs were developed that combine the advantages of ITO with those of $\mathrm{ZnO}$.

Integration of the novel light management techniques and new TCOs into high efficiency solar cells was one of main objectives of the project. We achieved thin film silicon solar cells with initial efficiencies of $13.2 \%$.

Finally, the project demonstrated the industrial scale feasibility of the developed technologies and materials. Cost of ownership calculations showed that implementation of these technologies on large scale would enable the production of these high efficiency solar modules at manufacturing cost of 65 Eurocents per Wp. Life cycle analysis showed that large scale production of modules based on the technologies developed in Silicon-Light would have an Energy Payback Time of 0.85 years in Central European countries.

This work was funded by the European FP7 project SiliconLight (GA No. 241277).

\section{References}

1. M. Sever, B. Lipovšek, J. Krč, A. Čampa, G. Sánchez Plaza, F.-J. Haug, M. Duchamp, W. Soppe, M. Topič, Sol. Energy Mater. Sol. Cells 119, 59 (2013)

2. M. Python, O. Madani, D. Domine, F. Meillaud, E. VallatSauvain, C. Ballif, Sol. Energy Mater. 93, 1714 (2009)

3. M. Sever et al., in Proceedings of the 27th EU PVSEC, 24-28 September 2012, pp. 2129-2131

4. M. Duchamp, M. Lachmann, C.B. Boothroyd, A. Kovacs, F.-J. Haug, C. Ballif, R.E. Dunin-Borkowski, Appl. Phys. Lett. 102, 133902 (2013)

5. R.W. Kelsall et al., Nanoscale Science and Technology (John Wiley \& Sons, Ltd, Chichester, 2005)

6. M. Duchamp et al., in Proceedings of the 26th EU PVSEC, 2011 , p. 2554

7. F.-J. Haug et al., MRS Symposium Proceedings 1321, 63 (2011)

8. F.-J. Haug, T. Söderström, O. Cubero, V. TerrazzoniDaudrix, C. Ballif, J. Appl. Phys. 104, 064509 (2008)

9. K. Söderström, F.-J. Haug, J. Escarré, C. Pahud, R. Biron, C. Ballif, Sol. Energy Mater. Solar Cells 95, 3585 (2011)

10. B. Van Aken, M. Duchamp, C. Boothroyd, R. DuninBorkowski, W. Soppe, J. Non-Cryst. Solids 358, 2179 (2012) 
W. Soppe et al.: Silicon-Light: a European project aiming at high efficiency thin film silicon solar cells on foil

11. M. Duchamp, C. Boothroyd, M. Moreno, B. van Aken, W. Soppe, R. Dunin-Borkowski, J. Appl. Phys. 113, 093513 (2013)

12. G. Stingeder, Anal. Chim. Acta 297, 231 (1994)

13. F.-J. Haug, R. Biron, G. Kratzer, F. Leresche, J. Besuchet, Ch. Ballif, M. Dissel, S. Kretschmer, W. Soppe, P. Lippens, K. Leitner, Prog. Photovolt.: Res. Appl. 20, 727 (2012)
14. W. Soppe, M. Dorenkamper, J.-B. Notta, P. Pex, W. Schipper, R. Wilde, Phys. Stat. Sol. A 210, 707 (2013)

15. R. Biron, C. Pahud, F.-J. Haug, J. Escarré, K. Söderström, C. Ballif, J. Appl. Phys. 110, 124511 (2011)

16. D. Richard, in Photon International, March 2010, p. 118

17. D. Richard, in Photon International, November 2010, p. 142

Cite this article as: W. Soppe, J. Krc, K. Leitner, F.-J. Haug, M. Duchamp, G. Sanchez Plaza, Q.-K. Wang, Silicon-Light: a European project aiming at high efficiency thin film silicon solar cells on foil, EPJ Photovoltaics 5, 55203 (2014). 